\title{
A High-Protein/Low-Fat Diet May Interact with Vitamin D-Binding Protein Gene Variants to Moderate the Risk of Depression in Apparently Healthy Adults
}

\author{
Sara Pooyan ${ }^{\mathrm{a}}$ Mohammad Hossein Rahimi ${ }^{\mathrm{a}}$ \\ Mehdi Mollahosseini ${ }^{\mathrm{a}} \quad$ Leila Khorrami-Nezhad $^{\mathrm{a}}$ Yasaman Nasir ${ }^{\mathrm{a}}$ \\ Zhila Maghbooli $^{b}$ Khadijeh Mirzaeia, b \\ a Department of Community Nutrition, School of Nutritional Sciences and Dietetics, Tehran University of \\ Medical Sciences (TUMS), Tehran, Iran; ${ }^{b}$ Osteoporosis Research Center, Endocrinology and Metabolism Clinical \\ Sciences Institute, Tehran University of Medical Sciences (TUMS), Tehran, Iran
}

\section{Keywords}

Dietary intake $\cdot$ Vitamin D-binding protein · Polymorphisms · Depression

\begin{abstract}
Background: Recent studies have shown that depression is inversely correlated with high protein and low fat intake and positively correlated with vitamin D-binding protein (VDBP). Therefore, the aim of this study was to examine the interaction between protein/fat dietary patterns and VDBP genotypes with regard to the risk of depression in apparently healthy adults who have not been diagnosed with any chronic disease. Methods: In this study, 265 individuals (126 males and 139 females) aged 18-55 years were recruited from the communities of central and west Tehran based on convenience sampling. Body composition was measured with a body composition analyzer and depression symptoms were categorized as normal, moderate depression, or severe depression using the Depression Anxiety Stress Scales 21 (DASS-21) questionnaire. Dietary patterns were determined by a semiquantitative food frequency question-
\end{abstract}

\section{KARGER}

(c) 2018 S. Karger AG, Basel

E-Mail karger@karger.com

www.karger.com/lfg naire to assess typical food intake during the 12-month period. Blood samples were collected from and biochemical measurements performed on all participants. An analysis of two polymorphisms (rs7041 and rs4588) in the GC gene, which encodes VDBP, was performed by polymerase chain reaction-restriction fragment length polymorphism. $\boldsymbol{R e}$ sults: A statistically significant association was found between depression and diet $(p=0.03)$ after having categorized the participants into three groups: a high-protein/lowfat (HP/LF) group, a moderate-protein/moderate-fat (MP/ MF) group, and a low-protein/high-fat (LP/HF) group. Moreover, the findings demonstrated that depression was related to both the rs7041 and the rs4588 polymorphism ( $p=$ 0.05 and $p=0.02$, respectively). We next used multinomial logistic modeling to investigate the risk of depression. A significant interaction was observed between HP/LF diet and the rs7041 polymorphism in the moderate- and severe-depression groups $(\beta=-0.30, p=0.05$, and $\beta=-0.48, p=0.01$, respectively). Conclusion: This study showed that an HP/LF diet interacts with the rs7041 polymorphism, with T allele carriers having a greater prevalence of moderate and severe depression.

(c) 2018 S. Karger AG, Basel
Khadijeh Mirzaei, $\mathrm{PhD}$

Department of Community Nutrition, School of Nutritional Sciences and Dietetics Tehran University of Medical Sciences (TUMS), P.O. Box 14155-6117 Tehran (Iran)

E-Mail mirzaei_kh@tums.ac.ir 


\section{Introduction}

Depression is a prevalent mental disorder and the second leading cause of global disability, with a high prevalence estimated at 350 million people worldwide [1]. Depression is characterized by a range of symptoms, including a loss of interest in daily activities for more than 2 weeks [1]. The outcomes associated with depressive disorders include a negative impact on relationships, families, and work. It has been estimated that depressive disorders are a significant cause of disease burden in both men and women $[1,2]$. Several epidemiological studies have reported that a low serum 25-hydroxy-vitamin D level is a risk factor for depression $[3,4]$.

Calcitriol $\left(1,25[\mathrm{OH}]_{2} \mathrm{D}_{3}\right)$ helps to maintain both the number of neurons and neuronal structure via detoxification mechanisms including inhibition of inducible nitric oxide synthase synthesis and increasing glutathione levels [5] and by regulating the synthesis of neurotrophins [ 6 , 7] - all of which are factors affecting the risk of depression. The effect of calcitriol on depression may be due to the presence of vitamin $\mathrm{D}$ receptor, vitamin $\mathrm{D}$-binding protein (VDBP), and/or 1-alpha-hydroxylase enzyme, which converts $25(\mathrm{OH}) \mathrm{D}_{3}$ to $1,25(\mathrm{OH})_{2} \mathrm{D}_{3}$ in the brain. These findings have encouraged efforts to describe the relationship between neuropsychiatric disorders and brain development [6].

In the present study, our goal was to examine the effects of polymorphisms in the GC gene, which encodes VDBP, and not of circulating VDBP levels. VDBP is found in human cerebrospinal fluid [8] and is a serum protein encoded by the GC gene - the main carrier protein responsible for the transfer of calcitriol to target neurons [2]; however, little is known about the role of VDBP in the central nervous system [9]. Two common functional single nucleotide polymorphisms (SNPs) are present in exon 11 of the GC gene, and they result in nucleotide substitutions in codon 416 (GAT to GAG; Asp to Glu; rs7041) and codon 420 (AAG to ACG; Thr to Lys; rs4588) [10]. The $\mathrm{T}$ allele in rs7041 and the A allele in rs4588 correspond to the risk alleles related to depression [11-14].

Many studies have established a relationship between diet and depression. For example, there is a relationship between high-protein/low-fat (HP/LF) diet and depression $[15,16]$. A number of studies have shown the effect of protein intake on depression $[16,17]$. The investigation into the effects of dietary protein intake on depression has centered on levels of serotonin and brain concentrations of tryptophan [17]. Plasma concentrations of
VDBP were found to be sensitive to dietary protein deficiency, though the mechanisms are unknown [18].

In the present study, the interaction between dietary protein/fat patterns and GC polymorphisms, as well as their effect on depression risk, were examined in a population of healthy Iranian adults free of chronic disease.

\section{Subjects and Methods}

\section{Participants}

The study subjects consisted of 265 individuals ( 126 males and 139 females) aged between 18 and 55 years who were recruited from all the regions of west and central Tehran, using communitybased convenience sampling [19]. The information was collected between May and September 2017. Exclusion criteria were pregnancy; being diagnosed with hepatic diseases such as viral hepatitis; thyroid, renal, or cardiovascular diseases; heart failure; malignancies; diabetes mellitus; being in any acute or chronic inflammatory state that affects inflammatory markers; having any kind of infection; being a current smoker; having a history of hypertension; or a self-reported indication of alcohol or drug abuse.

\section{Anthropometric Assessments}

For all participants in the study, weight $(\mathrm{kg})$, height $(\mathrm{cm})$, and waist circumference and hip circumference $(\mathrm{cm})$ were measured. Body weight was measured in light clothing with electronic scales, height was measured barefoot, and hip circumference was measured at the largest part of the hip over light clothing. Waist circumference was measured using an anthropometric tape by determining the distance midway between the lowest rib and the iliac crest with the subject standing $[20,21]$.

\section{Complete Body Composition Analysis}

The body composition of all individuals was assessed using a BC-418MA Segmental Body Composition Analyzer (Tanita, UK) [22]. Measurements included weight, BMI, fat mass, body fat percentage, abdominal fat mass, muscle mass, fat-free mass, and visceral fat mass. Total body water was obtained using bioelectrical impedance analysis. The participants had all fasted overnight (10$12 \mathrm{~h}$ ) and were barefoot when they were assessed by bioelectrical impedance analysis [19]. Taking measurements after strenuous exercise was avoided; the clinicians waited until the individuals had rested sufficiently in order to prevent possible differences in the measured values.

\section{Dietary Intake Assessment and HP/LF Diet Scoring}

The participants consumed their usual diet. Dietary intake was evaluated with the use of a valid and reliable [23], 147-item, semiquantitative food frequency questionnaire (FFQ) to assess the usual food intake of individuals during the previous 12 months. The consumption frequency of each food item on a daily, weekly, or monthly basis was converted into daily intakes; portion sizes were then converted to grams and milliliters using Nutritionist software $(\mathrm{Nu}-$ tritionist version 4.0; Tinuviel Software, Warrington, UK). Eventually, total energy intake was calculated with this software. Protein/ fat dietary patterns were calculated according to the following method. Using data obtained from the FFQ, the amount of protein and 
fat intake was determined and the percentage of protein and fat intake was calculated using the following formulae: (protein intake $[\mathrm{g}] \times 4 / \mathrm{kcal}) \times 100$ and $($ fat intake $[\mathrm{g}] \times 9 / \mathrm{kcal}) \times 100$. The rank method for tertile scoring was used. The tertile scoring of protein intake was done as follows: (1) high protein intake, (2) moderate protein intake, and (3) low protein intake; the tertile scoring was the opposite for fat intake. Then, the scores were pooled together, and the final score was tertiled into (1) an HP/LF, (2) a moderate-protein/moderate-fat (MP/MF), and (3) a low-protein/high-fat (LP/ $\mathrm{HF}$ ) pattern. The mean protein percentage in the HP/LF, MP/MF, and LP/HF dietary patterns was $16.9,14.7$, and $12.7 \%$, respectively.

\section{Depression Symptoms}

Data were collected using the Depression Anxiety Stress Scales 21 (DASS-21) questionnaire. This questionnaire is a psychological screening instrument which is able to differentiate between symptoms of depression, stress, and anxiety. It is a reliable and validated tool with 21 items in three domains (depression, anxiety, and stress) [24]. The individuals were asked to indicate the presence of symptoms related to each dimension over the past week, scored from 0 to 3 . The scores on each domain were added together and then categorized based on the DASS manual as normal, moderate depression, or severe depression [25].

\section{Blood Pressure Measurement}

Resting blood pressure was measured after 15 min seated in a chair by the same person. Blood pressure was measured using an Automatic Inflate Blood Pressure Monitor (Samsung BA507S Automatic Digital Blood Pressure Monitor; Samsung America, Inc.).

\section{Laboratory Measurements}

All of the participants were referred to Shariati Hospital's outpatient clinic. All baseline blood samples were collected between 8:00 and 10:00 in the morning, following 10-12 h of overnight fasting. After centrifugation, serum was isolated and stored at a temperature of $-80^{\circ} \mathrm{C}$. All measurements were performed at the Endocrinology and Metabolism Research Center Laboratory of Shariati Hospital.

\section{Biochemical Measurements}

The GPO-PAP (glycerol-3-phosphate oxidase phenol 4-aminoantipyrine peroxidase) method was used for the measurement of triglyceride (TG) levels, and fasting serum glucose was measured by the GOD-PAP (glucose oxidase phenol 4-aminoantipyrine peroxidase) method [20]. Total cholesterol (TC) levels as well as direct high-density lipoprotein (HDL) cholesterol and low-density lipoprotein (LDL) cholesterol were measured with an enzymatic clearance assay and the enzymatic endpoint method, respectively. All measurements were performed using Randox laboratory kits (Randox Laboratories Ltd., Ardmore, UK). Serum 1,25(OH) ${ }_{2} \mathrm{D}_{3}$ was measured using a BioSource kit (BioSource Europe SA, Nivelles, Belgium) by the radioimmunoassay method. Serum high-sensitivity C-reactive protein (hs-CRP) was assessed by the immunoturbidimetric assay method (high-sensitivity assay; Hitachi 902). Quality control for all biochemical assessments was performed using control serum, as per the manufacturers' instructions.

Polymorphism Analysis of the GC Gene

Genomic DNA was extracted from $200 \mathrm{~mL}$ of whole blood using the GeneAll Mini Columns Type kit (GeneAll, South Korea). The extracted DNA was used to assess the rs4588 and rs7041 SNPs located in the GC gene. Polymerase chain reaction (PCR) was performed on the rs4588 and rs7041 SNPs using forward and reverse primers: forward, 5'-CAAGTCTTATCACCATCCTG-3'; reverse, $5^{\prime}$-GCCAAGTTACAATAACAC-3'. PCR was carried out on a total volume of $20 \mu \mathrm{L}$, which included 10 pmol of each primer, $50 \mathrm{ng} /$ $\mathrm{mL}$ of DNA, and $1 \mathrm{M}$ of dimethyl sulfide.

The amplification protocol consisted of a primary denaturation step at $94^{\circ} \mathrm{C}$ for $5 \mathrm{~min}$, followed by 35 cycles of denaturation at $60^{\circ} \mathrm{C}$ for $1 \mathrm{~min}$, annealing at $94^{\circ} \mathrm{C}$ for $45 \mathrm{~s}$, and extension at $72^{\circ} \mathrm{C}$ for $1 \mathrm{~min}$, and final extension at $72^{\circ} \mathrm{C}$ for $10 \mathrm{~min}$. To auscultate the SNPs rs4588 (Asp, 416, Glu) and rs7041 (Thr, 420, Lys), StyI and HaeIII enzymes were used as follows: for HaeIII, PCR product $5 \mu \mathrm{L}$, HaeIII $1 \mu \mathrm{L}$, Buffer Y/Tango $10 \times 1 \mu \mathrm{L}$, and distilled water (D.W.) $8 \mu \mathrm{L}$, and for StyI, PCR product $5 \mu \mathrm{L}$, StyI $1 \mu \mathrm{L}$, Buffer Y/ Tango $10 \times 1 \mu \mathrm{L}$, and D.W. $8 \mu \mathrm{L}$.

The digestion products were stained with ethidium bromide on a $2 \%$ agarose gel and imaged. Individuals homozygous for the Asp allele had a nondigested band at $809 \mathrm{bp}$, while those homozygous for the Glu allele showed two bands (577 and $232 \mathrm{bp}$ ) in the GC gene (rs7041). The homozygous Lys allele showed two bands (584 and $225 \mathrm{bp}$ ), while the Thr allele in rs 4588 appeared as a single band (809 bp). Haplotypes were determined by observing the digestion products of both restriction enzymes. GC $1 \mathrm{~S}$ has the HaeIII but not the StyI site. GC 1F has neither the HaeIII nor the StyI site. GC 2 has the StyI but not the HaeIII site. The existence of both restriction sites on a single haplotype has not yet been characterized [26].

\section{Statistical Analysis}

Data and statistical analyses were performed using the SPSS 20 statistical package (SPSS Inc., Chicago, IL, USA). According to the Peduzzi method, the sample size was estimated using a binary logistic equation [27]. Normal data distribution was determined using the Kolmogorov-Smirnov test. Individuals were categorized according to depression scores. The rank method was used for tertile scoring of the three dietary groups (HP/LF, MP/MF, and LP/HF).

A general linear model and ANOVA were used to assess differences in biochemical measurements and characteristics between depression groups, dietary patterns, and rs7041 and haplotype groups. A general linear model adjusted for age, BMI, total energy, and systolic and diastolic blood pressure as confounder effects was used. An independent-samples $t$ test was used to assess differences between the two rs 4588 groups in biochemical measurements and characteristics. Coding of the SNPs was performed using an additive model.

Multinomial logistic regression analysis was carried out to assess interactions between VDBP and protein/fat dietary patterns, and it was adjusted for differences in age, sex, and BMI. The study population characteristics are reported as mean \pm standard deviation (SD). Statistical significance was defined as $p \leq 0.05$ for all analyses.

\section{Results}

\section{Study Population Characteristics}

The participants in the current study were apparently healthy, with a mean age, weight, height, and BMI of $35.08 \pm 8.78$ years, $73.51 \pm 15.66 \mathrm{~kg}, 168.23 \pm 9.43 \mathrm{~cm}$, and $25.93 \pm 4.89$, respectively.
66 
Table 1. Baseline characteristics and biochemical measurements among participants separated according to depression status

\begin{tabular}{|c|c|c|c|c|c|}
\hline Characteristics & Normal & Moderate depression & Severe depression & $p^{1}$ & $p^{2}$ \\
\hline Age, years & $35.44 \pm 9.04$ & $34.84 \pm 8.94$ & $35.42 \pm 7.95$ & 0.88 & 0.76 \\
\hline Sex, $n(\%)$ & $128(51)$ & $81(32)$ & $40(16)$ & $0.01^{*}$ & 0.22 \\
\hline \multicolumn{6}{|l|}{ Anthropometrics } \\
\hline Weight, kg & $72.93 \pm 16.31$ & $74.95 \pm 14.62$ & $72.25 \pm 16.67$ & 0.58 & 0.386 \\
\hline Height, $\mathrm{cm}$ & $167.89 \pm 9.01$ & $169.24 \pm 9.89$ & $166.93 \pm 10.11$ & 0.40 & 0.906 \\
\hline Waist circumference, $\mathrm{cm}$ & $88.35 \pm 12.91$ & $89.87 \pm 11.88$ & $88.84 \pm 12.84$ & 0.70 & $0.04^{*}$ \\
\hline BMI & $25.86 \pm 5.17$ & $26.11 \pm 4.52$ & $25.76 \pm 4.58$ & 0.91 & 0.362 \\
\hline Fat percentage & $25.88 \pm 9.15$ & $25.08 \pm 9.58$ & $25.20 \pm 9.26$ & 0.82 & $0.002 *$ \\
\hline $\mathrm{SBP}, \mathrm{mm} \mathrm{Hg}$ & $11.96 \pm 1.20$ & $11.98 \pm 1.23$ & $11.80 \pm 1.41$ & 0.77 & 0.650 \\
\hline $\mathrm{DBP}, \mathrm{mm} \mathrm{Hg}$ & $7.82 \pm 0.88$ & $7.68 \pm 0.93$ & $7.64 \pm 0.96$ & 0.43 & $0.006^{*}$ \\
\hline \multicolumn{6}{|l|}{ Biochemical tests } \\
\hline HDL-C, mg/dL & $48.46 \pm 12.25$ & $48.80 \pm 11.26$ & $48.95 \pm 12.38$ & 0.96 & 0.097 \\
\hline ALT, IU/L & $16.51 \pm 12.14$ & $18.32 \pm 10.66$ & $16.12 \pm 8.62$ & 0.44 & 0.531 \\
\hline $\mathrm{FBS}, \mathrm{mmol} / \mathrm{L}$ & $95.79 \pm 23.23$ & $93.90 \pm 14.98$ & $89.82 \pm 7.46$ & 0.22 & $0.008^{*}$ \\
\hline hs-CRP, mg/L & $2.28 \pm 3.44$ & $2.41 \pm 3.60$ & $2.35 \pm 2.73$ & 0.96 & 0.890 \\
\hline $1,25(\mathrm{OH})_{2} \mathrm{D}_{3}, \mathrm{nmol} / \mathrm{L}$ & $20.74 \pm 12.91$ & $25.65 \pm 30.94$ & $23.09 \pm 16.27$ & 0.40 & 0.34 \\
\hline
\end{tabular}

Values are presented as mean \pm SD unless specified otherwise. SBP, systolic blood pressure; DBP, diastolic blood pressure; HDL-C, high-density lipoprotein cholesterol; LDL-C, low-density lipoprotein cholesterol; TC, total cholesterol; TG, triglyceride; AST, aspartate transaminase; ALT, alanine transaminase; FBS, fasting blood sugar; hs-CRP, high-sensitivity C-reactive protein. ${ }^{*} p<0.05 .{ }^{1} p$ value of ANOVA. ${ }^{2} p$ value of ANCOVA after adjustment for age, sex, BMI, and total energy.

\section{Association between the Clinical and Biochemical Characteristics of the Participants and Depression Status}

Table 1 presents the clinical and biochemical characteristics of the 265 participants (126 males and 139 females). The subjects were categorized based on depression status and divided into three groups: normal, moderate depression, and severe depression. ANOVA revealed that there were no statistically significant differences between the three depression status groups in demographic characteristics and biochemical measurements; however, the sex ratio was significantly different $(p=0.01)$. After adjusting for age, BMI, total energy, and systolic and diastolic blood pressure using the general linear model, the relationships between depression status and waist circumference $(p=$ $0.04)$, fat percentage ( $p=0.002)$, diastolic blood pressure $(p=0.006)$, LDL $(p=0.03)$, TG $(p=0.006)$, and fasting blood sugar (FBS; $p=0.008$ ) were statistically significant. However, a post hoc analysis was unable to show statistically significant differences between the groups. Nevertheless, in the severe depression group, waist circumference and LDL tended to be more similar to the values of the normal group, while fat percentage, diastolic blood pressure, TG, and FBS in the severe depression group were less similar to the values of the normal group.

\section{HP/LF Diet}

A validated, 147-item, semiquantitative FFQ was employed to assess dietary intake [23]. In order to estimate the protein/fat dietary pattern, the participants were categorized according to their protein and fat consumption. The sources of dietary protein included red meat, processed red meat, poultry, full-fat dairy, low-fat dairy, fish, eggs, and legumes. Table 2 shows the age, weight, height, BMI, waist and hip circumference, fat percent, systolic and diastolic blood pressure, protein intake, and biochemical measurements for the HP/LF, MP/MF, and LP/HF groups.

After categorization, statistically significant differences were observed in age $(p=0.001)$, depression score $(p=$ $0.03)$, weight $(p<0.001)$, height $(p<0.001)$, systolic blood pressure $(p<0.001)$, diastolic blood pressure $(p=0.006)$, HDL $(p=0.004)$, LDL $(p=0.001)$, TC $(p<0.001)$, TG 
Table 2. Characteristics of the participants separated into protein/fat dietary pattern groups

\begin{tabular}{|c|c|c|c|c|c|}
\hline Characteristics & $\mathrm{HP} / \mathrm{LF}$ & $\mathrm{MP} / \mathrm{MF}$ & $\mathrm{LP} / \mathrm{HF}$ & $p^{1}$ & $p^{2}$ \\
\hline Age, years & $35.07 \pm 8.70^{\mathrm{a}}$ & $34.06 \pm 8.84^{\mathrm{b}}$ & $36.68 \pm 8.69^{\mathrm{a}, \mathrm{b}}$ & $0.001^{*}$ & $<0.001^{*}$ \\
\hline Depression status & & & & $0.03^{*}$ & 0.29 \\
\hline Normal & $51.2 \%$ & $50.3 \%$ & $53.4 \%$ & & \\
\hline Moderate depression & $41.0 \%$ & $31.2 \%$ & $31.0 \%$ & & \\
\hline Weight, kg & $73.46 \pm 14.38^{\mathrm{c}}$ & $71.90 \pm 16.67^{\mathrm{d}}$ & $76.63 \pm 14.22^{\mathrm{c}, \mathrm{d}}$ & $<0.001^{*}$ & $0.002 *$ \\
\hline Height, cm & $167.61 \pm 9.19^{\mathrm{e}}$ & $167.47 \pm 8.85^{\mathrm{f}}$ & $171.04 \pm 10.41^{\mathrm{e}, \mathrm{f}}$ & $<0.001^{*}$ & $<0.001^{*}$ \\
\hline Waist circumference, $\mathrm{cm}$ & $88.40 \pm 11.80$ & $87.84 \pm 13.07^{g}$ & $89.98 \pm 11.56^{\mathrm{g}}$ & 0.09 & 0.39 \\
\hline Hip circumference, $\mathrm{cm}$ & $101.70 \pm 7.45^{\mathrm{h}}$ & $102.28 \pm 10.68$ & $103.40 \pm 8.22^{\mathrm{h}}$ & 0.14 & $0.005^{*}$ \\
\hline BMI & $26.00 \pm 3.75$ & $25.59 \pm 5.29$ & $26.21 \pm 4.72$ & 0.21 & 0.47 \\
\hline Fat percentage & $26.01 \pm 7.16$ & $25.33 \pm 10.04$ & $25.31 \pm 9.39$ & 0.64 & 0.12 \\
\hline LDL-C, mg/dL & $103.65 \pm 26.24^{\circ}$ & $98.07 \pm 23.42^{\mathrm{o}, \mathrm{p}}$ & $104.74 \pm 31.94^{\mathrm{p}}$ & $0.001^{*}$ & 0.06 \\
\hline $\mathrm{TC}, \mathrm{mg} / \mathrm{dL}$ & $189.08 \pm 38.38^{q}$ & $179.39 \pm 36.06^{\mathrm{q}, \mathrm{r}}$ & $189.83 \pm 44.51^{\mathrm{r}}$ & $<0.001^{*}$ & $0.007^{*}$ \\
\hline $\mathrm{TG}, \mathrm{mmol} / \mathrm{L}$ & $154.17 \pm 119.74^{\mathrm{s}, \mathrm{t}}$ & $108.86 \pm 54.86^{\mathrm{s}, \mathrm{u}}$ & $133.87 \pm 115.34^{\mathrm{t}, \mathrm{u}}$ & $<0.001^{*}$ & $<0.001^{*}$ \\
\hline AST, IU/L & $19.84 \pm 5.38$ & $20.42 \pm 7.46$ & $20.41 \pm 5.80$ & 0.52 & 0.81 \\
\hline ALT, IU/L & $16.98 \pm 5.38$ & $16.65 \pm 13.05$ & $17.90 \pm 8.41$ & 0.33 & 0.71 \\
\hline $\mathrm{FBS}, \mathrm{mmol} / \mathrm{L}$ & $96.00 \pm 27.83^{\mathrm{v}}$ & $92.86 \pm 16.83^{\mathrm{v}}$ & $95.19 \pm 11.02$ & 0.06 & 0.25 \\
\hline hs-CRP, mg/L & $1.85 \pm 2.21^{\mathrm{w}}$ & $2.66 \pm 4.02^{\mathrm{w}, \mathrm{x}}$ & $1.86 \pm 2.27^{\mathrm{x}}$ & $0.001^{*}$ & $0.001^{*}$ \\
\hline $1,25(\mathrm{OH})_{2} \mathrm{D}_{3}, \mathrm{nmol} / \mathrm{L}$ & $2.11 \pm 1.35^{y}$ & $1.71 \pm 0.94$ & $1.41 \pm 1.25^{\mathrm{y}}$ & $0.001^{*}$ & 0.94 \\
\hline
\end{tabular}

Values are presented as mean \pm SD unless specified otherwise. HP/LF, high-protein/low-fat; MP/MF, moderate-protein/moderatefat; LP/HF, low-protein/high-fat; SBP, systolic blood pressure; DBP, diastolic blood pressure; HDL-C, high-density lipoprotein cholesterol; LDL-C, low-density lipoprotein cholesterol; TC, total cholesterol; TG, triglyceride; AST, aspartate transaminase; ALT, alanine transaminase; FBS, fasting blood sugar; hs-CRP, high-sensitivity C-reactive protein. ${ }^{*} p<0.05 .{ }^{1} p$ value of ANOVA. ${ }^{2} p$ value of ANCOVA after adjustment for age, sex, BMI, and total energy.

$(p<0.001)$, and hs-CRP $(p=0.001)$. After factoring in age, sex, BMI, total energy, and systolic and diastolic blood pressure, significant differences were preserved between the three groups for age $(p<0.001)$, protein intake $(p<$ $0.0001)$, weight $(p=0.002)$, height $(p<0.001)$, hip circumference $(p=0.005)$, systolic blood pressure $(p<0.001)$, diastolic blood pressure $(p=0.001)$, HDL $(p=0.002)$, TC $(p<0.007), \mathrm{TG}(p<0.001)$, and hs-CRP $(p=0.001)$. The percentage of severe depression among the participants in the HP/LF group $(7.8 \%)$ was significantly lower than among the individuals in the LP/HF group (15.5\%).

\section{Characteristics and Biochemical Measurements among Different GC Genotypes}

In the multinomial model, sex, age, and BMI were considered as dependent. When analyzing individuals based on the rs7041 and rs4588 polymorphisms, the partici- pants were divided into three and two groups, respectively (rs7041: GG, TG, and TT; rs4588: CC and AC+AA), while in the haplotype model individuals were categorized into four groups (TC, GA, GC, and TA). The present study revealed rs7041 as being significantly associated with depression score $(p=0.05)$, weight $(p=0.008)$, height $(p=0.001)$, hip circumference $(p=0.01)$, systolic blood pressure $(p=0.002)$, diastolic blood pressure $(p=$ $0.01)$, LDL $(p<0.001)$, TC $(p<0.001)$, TG $(p=0.04)$, AST $(p<0.001)$, ALT $(p<0.001)$, FBS $(p<0.001)$, and hs-CRP $(p=0.04)$. The mean depression score among the participants with the TG genotype was higher than in the individuals with either the TT or the GG genotype.

In the present study, rs 4588 was positively associated with depression score $(p=0.02)$, weight $(p=0.002)$, height $(p=0.003)$, waist circumference $(p=0.02)$, hip circumference $(p=0.003)$, HDL $(p=0.03)$, LDL $(p=0.005)$, 
Table 3. Interaction between HP/LF diet and GC genotypes

\begin{tabular}{lllll}
\hline & & $\beta \pm \mathrm{SE}$ & OR $(95 \% \mathrm{CI})$ & $p^{1}$ \\
\hline rs7041 & & & & \\
Crude model & moderate & $-0.30 \pm 0.15$ & $0.73(0.54-1.00)$ & $0.05^{*}$ \\
& severe & $-0.48 \pm 0.20$ & $0.61(0.41-0.92)$ & $0.01^{*}$ \\
Adjusted model & moderate & $-0.25 \pm 0.16$ & $0.77(0.56-1.06)$ & 0.11 \\
& severe & $-0.47 \pm 0.21$ & $0.62(0.41-0.93)$ & $0.02^{*}$ \\
\hline rs4588 & & & $0.77(0.50-1.18)$ & 0.23 \\
Crude model & moderate & $-0.26 \pm 0.21$ & $0.75(0.42-1.35)$ & 0.35 \\
Adjusted model & severe & $-0.27 \pm 0.29$ & $0.73(0.47-1.13)$ & 0.16 \\
& moderate & $-0.30 \pm 0.22$ & $0.78(0.43-1.41)$ & 0.42 \\
\hline Haplotype & severe & $-0.24 \pm 0.30$ & & $0.91(0.77-1.06)$ \\
Crude model & moderate & $-0.92 \pm 0.08$ & $0.84(0.68-1.03)$ & 0.24 \\
Adjusted model & severe & $-0.17 \pm 0.10$ & $0.92(0.79-1.08)$ & 0.36 \\
& moderate & $-0.07 \pm 0.08$ & $0.84(0.68-1.04)$ & 0.11 \\
\hline
\end{tabular}

We consider the normal as reference. Adjusted model: after adjustment for age, sex, and BMI. HP/LF, highprotein/low-fat. ${ }^{*} p<0.05 .{ }^{1} p$ value of multinomial logistic regression analysis.

$\operatorname{AST}(p<0.001)$, and ALT $(p=0.006)$. After categorization, the individuals in the haplotype model had significant associations with hip circumference $(p=0.03)$ and $\operatorname{AST}(p=0.01)$. However, there were no significant associations in the haplotype model regarding other measurements $(p>0.05)$. The depression scores of the participants with the GA and TA genotypes in the haplotype model were not significantly lower than those of the participants with GC and TC alleles.

Interaction between GC Genotype and HP/LF Diet regarding Depression Risk

Multinomial logistic regression analysis was performed to determine the interaction between HP/LF diet and the various genotypes related to the two SNPs (rs4588 and rs7041) with regard to depression (Table 3). There was no considerable heterogeneity in the interaction between HP/LF diet and rs4588 polymorphism and the haplotype model in the depression groups before and after adjustment for age, sex, and BMI $(p>0.05)$. However, a significant interaction was noted between HP/LF diet and rs7041 polymorphism in the moderate- and severe-depression groups before and after controlling for covariates $(p=$ $0.05, \mathrm{OR}=0.73,95 \% \mathrm{CI} 0.54-1.00$, and $p=0.01, \mathrm{OR}=0.61$, $95 \%$ CI $0.41-0.92$, respectively). For the rs7041 polymorphism, the interaction with the severe-depression group was higher than with the moderate-depression group (se-

Effect of HP/LF Diet and Variants of VDBP on Depression Risk vere-depression group: $\beta=-0.48,95 \%$ CI $0.41-0.91, p=$ 0.01 ). Also, in Figure 1, a considerable interaction between $\mathrm{HP} / \mathrm{LF}$ diet and rs7041 polymorphism was seen, with the percentage of depressed participants with the risk allele $\mathrm{T}$ being greater $(50 \%$ in the moderate-depression group and $10 \%$ in the severe-depression group).

\section{Discussion}

This cross-sectional study demonstrated that an HP/ LF diet may interact with the VDBP genotype to moderate the depression risk in apparently healthy adults free of chronic disease. Three depression statuses were determined: normal, moderate depression, and severe depression. After categorization, individuals consuming an HP/ LF diet demonstrated statistically significant differences in depression scores. These findings demonstrate that depression scores correlated with rs7041 and rs4588 polymorphisms, and that there was a strong interaction between HP/LF diet and being a T allele carrier for rs7041 in the moderate- and severe-depression groups. However, we did not identify an interaction between the HP/LF dietary pattern and rs4588.

Depression may be associated with lipid profiles and inflammatory cytokines $[28,29]$. In this study, after categorization by depression status, a significant association was 


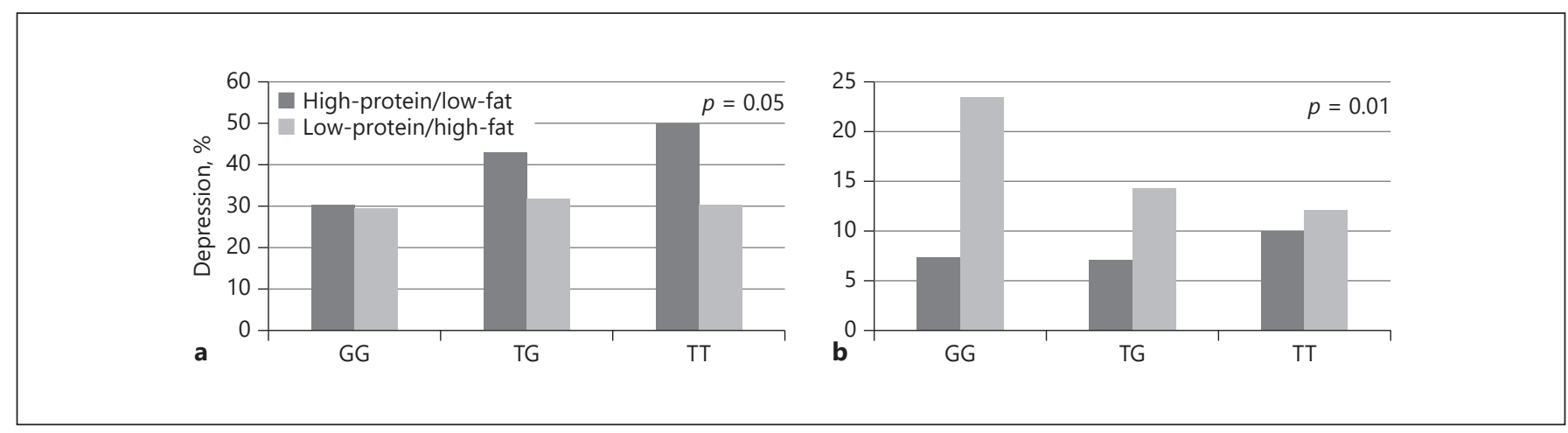

Fig. 1. A significant interaction was noted between high-protein/ low-fat diet and rs7041 polymorphism in the moderate- and severe-depression groups. The normal group was considered as the reference group. Regarding rs7041 polymorphism, the interaction in the moderate-depression group (a) was weaker than in the severe-depression group (b). The frequency of the TT genotype among the depressed participants was higher than the frequencies of the other genotypes. The number of participants in the moderate-depression group was 81 (GG, $n=16$; TG, $n=25$; TT, $n=40$ ), and in the severe-depression group there were 40 subjects (GG, $n=4$; TG, $n=16$; TT, $n=20$ ).

tigation into the effects of protein intake on behavior and mood has focused on levels of tryptophan and serotonin [17]. Indeed, tryptophan has an antidepressant-like effect through its conversion into serotonin [36]. Given this connection, a high protein intake may have a greater beneficial effect on mental health [33].

In the present study, we demonstrated that rs7041 polymorphism was associated with depression and weight, height, hip circumference, systolic and diastolic blood pressure, LDL, TC, TG, AST, ALT, FBS, and hs-CRP, while rs4588 polymorphism was correlated with depression and waist circumference, LDL, TC, TG, AST, and ALT. These findings are in contrast to those of previous studies. For example, some prior studies have observed no relationship between various biochemical measures and rs7041 or rs4588 [37, 38]. This contradiction in findings may be due to the imbalance between the two populations, as well as the low prevalence of the SNPs. However, Lee et al. [2] reported significant associations between GC gene expression levels, depression symptoms, and serum lipid profiles. The distribution of neurons targeted by calcitriol suggests an influence of synthesis levels of acetylcholine acetylase, testosterone, and serotonin $[39,40]$, which have all been linked to the pathogenesis of depression. Specifically, a reduction in neurotransmitters has been related to an enhanced risk of depression.

The current study also suggests that there is an interaction between HP/LF diet and rs7041 in moderate- and severe-depression groups, as well as showing a strong interaction between the T allele in rs7041 and a HP/LF diet. The $\mathrm{T}$ allele in rs7041 has been reported as a risk allele 
[41]. It seems that the depression rates among the participants carrying the $\mathrm{T}$ allele were higher. In contrast, we found no association between HP/LF diet and rs 4588 polymorphism. These findings have considerable significance in view of the high prevalence of low-protein diets and VDBP genotype changes among apparently healthy depressed adults. This could lead to practical strategies to help with the control or prevention of depression. The researchers' interpretation of the associations described in the present study will require interventional studies in order to provide causal evidence.

The main limitation of the present study is its basis on a sample size, which led to insufficient numbers of participants in some subgroups for genotype categorization. The strength of the current study is that - to the best of our knowledge - it is the first to evaluate interactions between GC gene variants and protein/fat dietary patterns in apparently healthy depressed subjects.

\section{Conclusions}

The current study suggests that an HP/LF diet may interact with the rs7041 genotype in moderate and severe depression. Also, another important finding of this study is that there was an interaction effect identified in carriers of the T allele in rs7041 with HP/LF diet.

\section{Acknowledgements}

The study was supported by grants from the Tehran University of Medical Sciences (Grant IDs: 93-04-159-28031, 96-01-15934988, and 93-04-161-27722). The authors thank the managers of the School of Nutritional Sciences and Dietetics and the Endocrinology and Metabolism Research Center, Tehran University of Medical Sciences, for giving clearance for the current project.

\section{Statement of Ethics}

All individuals gave their informed, written consent to participate in the study. The study was approved by the Ethics Committee of the Endocrinology and Metabolism Research Center of the Tehran University of Medical Sciences (Ethics No. 93-04-159-28031144521).

\section{Disclosure Statement}

The authors declare no conflicts of interest.

\section{Author Contributions}

Study concept and design: K.M. and S.P.; data acquisition: K.M., S.P., M.H.R., M.M., L.K.-N., and Z.M.; data analysis and interpretation: K.M. and Z.M.; drafting of the manuscript: S.P., Y.N., M.H.R., M.M., and L.K.-N.

\section{References}

1 Shafiee M, Tayefi M, Hassanian SM, Ghaneifar Z, Parizadeh MR, Avan A, et al. Depression and anxiety symptoms are associated with white blood cell count and red cell distribution width: A sex-stratified analysis in a population-based study. Psychoneuroendocrinology. 2017 Oct;84:101-8.

2 Lee MY, Kim EY, Kim SH, Cho KC, Ha K, Kim KP, et al. Discovery of serum protein biomarkers in drug-free patients with major depressive disorder. Prog Neuropsychopharmacol Biol Psychiatry. 2016 Aug;69:60-8.

3 Banerjee A, Khemka VK, Roy D, Dhar A, Sinha Roy TK, Biswas A, et al. Role of ProInflammatory Cytokines and Vitamin D in Probable Alzheimer's Disease with Depression. Aging Dis. 2017 May;8(3):267-76.

4 Milaneschi Y, Hoogendijk W, Lips P, Heijboer AC, Schoevers R, van Hemert AM, et al. The association between low vitamin $\mathrm{D}$ and depressive disorders. Mol Psychiatry. 2014 Apr;19(4):444-51.
5 Garcion E, Wion-Barbot N, Montero-Menei CN, Berger F, Wion D. New clues about vitamin $\mathrm{D}$ functions in the nervous system. Trends Endocrinol Metab. 2002 Apr;13(3): $100-5$.

6 Can MS, Baykan H, Baykan Ö, Erensoy N, Karlidere T. Vitamin D Levels and Vitamin D Receptor Gene Polymorphism in Major Depression. Psychiatr Danub. 2017 Jun;29(2): 179-85.

7 Puchacz E, Stumpf WE, Stachowiak EK, Stachowiak MK. Vitamin D increases expression of the tyrosine hydroxylase gene in adrenal medullary cells. Brain Res Mol Brain Res. 1996 Feb;36(1):193-6.

8 Petrov B, Aldoori A, James C, Yang K, Algorta GP, Lee A, et al. Bipolar disorder in youth is associated with increased levels of vitamin D-binding protein. Transl Psychiatry. 2018 Mar 13;8(1):61.
9 Park Y, Kim YS, Kang YA, Shin JH, Oh YM, Seo JB, et al. Relationship between vitamin Dbinding protein polymorphisms and blood vitamin $\mathrm{D}$ level in Korean patients with COPD. Int J Chron Obstruct Pulmon Dis. 2016 Apr;11:731-8.

10 Agliardi C, Guerini FR, Zanzottera M, Bolognesi E, Costa AS, Clerici M. Vitamin D-binding protein gene polymorphisms are not associated with MS risk in an Italian cohort. J Neuroimmunol. 2017 Apr;305:92-5.

11 Lu L, Sheng H, Li H, Gan W, Liu C, Zhu J, et al. Associations between common variants in GC and DHCR7/NADSYN1 and vitamin D concentration in Chinese Hans. Hum Genet. 2012 Mar;131(3):505-12.

12 Engelman CD, Fingerlin TE, Langefeld CD, Hicks PJ, Rich SS, Wagenknecht LE, et al. Genetic and environmental determinants of 25-hydroxyvitamin D and 1,25-dihydroxyvitamin D levels in Hispanic and African Americans. J Clin Endocrinol Metab. 2008 Sep; 93(9):3381-8. 
13 Robien K, Butler LM, Wang R, Beckman KB, Walek D, Koh WP, et al. Genetic and environmental predictors of serum 25-hydroxyvitamin D concentrations among middle-aged and elderly Chinese in Singapore. Br J Nutr. 2013 Feb;109(3):493-502.

14 Santos BR, Mascarenhas LP, Boguszewski MC, Spritzer PM. Variations in the vitamin D-binding protein (DBP) gene are related to lower 25-hydroxyvitamin D levels in healthy girls: a cross-sectional study. Horm Res Paediatr. 2013;79(3):162-8.

15 Alwerdt J, Small BJ. Fecal incontinence as a moderator between dietary intake and depressive symptoms among a sample of older adults obtained from the National Health and Nutrition Examination Survey (NHANES). Aging Ment Health. 2017. [Epub ahead of print]

16 Chang MW, Brown R, Nitzke S, Smith B, Eghtedary K. Stress, sleep, depression and dietary intakes among low-income overweight and obese pregnant women. Matern Child Health J. 2015 May;19(5):1047-59.

17 Wolfe AR, Arroyo C, Tedders SH, Li Y, Dai Q, Zhang J. Dietary protein and protein-rich food in relation to severely depressed mood: A 10 year follow-up of a national cohort. Prog Neuropsychopharmacol Biol Psychiatry. 2011 Jan;35(1):232-8.

18 Laing CJ, Fraser DR. Changes with malnutrition in the concentration of plasma vitamin D binding protein in growing rats. Br J Nutr. 2002 Aug;88(2):133-9.

19 Mollahosseini M, Daneshzad E, Rahimi MH, Yekaninejad MS, Maghbooli Z, Mirzaei K. The Association between Fruit and Vegetable Intake and Liver Enzymes (Aspartate and Alanine Transaminases) in Tehran, Iran. Ethiop J Health Sci. 2017 Jul;27(4):401-10.

20 Mirzababaei A, Mirzaei K, Khorrami-Nezhad L, Maghbooli Z, Keshavarz SA. Metabolically healthy/unhealthy components may modify bone mineral density in obese people. Arch Osteoporos. 2017 Oct;12(1):95.

21 WHO Multicentre Growth Reference Study Group. Reliability of anthropometric measurements in the WHO Multicentre Growth Reference Study. Acta Paediatr Suppl. 2006 Apr;450:38-46.
22 Moradi S, Mirzaei K, Abdurahman AA, Keshavarz SA, Hossein-Nezhad A. Mediatory effect of circulating vaspin on resting metabolic rate in obese individuals. Eur J Nutr. 2016 Apr;55(3):1297-305.

23 Asghari G, Rezazadeh A, Hosseini-Esfahani F, Mehrabi Y, Mirmiran P, Azizi F. Reliability, comparative validity and stability of dietary patterns derived from an FFQ in the Tehran Lipid and Glucose Study. Br J Nutr. 2012 Sep; 108(6):1109-17.

24 Rusli BN, Amrina K, Trived S, Loh KP, Shashi $\mathrm{M}$. Construct validity and internal consistency reliability of the Malay version of the 21item depression anxiety stress scale (MalayDASS-21) among male outpatient clinic attendees in Johor. Med J Malaysia. 2017 Oct; 72(5):264-70

25 Tonsing KN. Psychometric properties and validation of Nepali version of the Depression Anxiety Stress Scales (DASS-21). Asian J Psychiatr. 2014 Apr;8:63-6.

26 Borges CR, Rehder DS, Jarvis JW, Schaab MR, Oran PE, Nelson RW. Full-length characterization of proteins in human populations. Clin Chem. 2010 Feb;56(2):202-11.

27 Peduzzi P, Concato J, Kemper E, Holford TR, Feinstein AR. A simulation study of the number of events per variable in logistic regression analysis. J Clin Epidemiol. 1996 Dec;49(12): 1373-9.

28 Gohar SM, Dieset I, Steen NE, Mørch RH, Iversen TS, Steen VM, et al. Association between serum lipid levels, osteoprotegerin and depressive symptomatology in psychotic disorders. Eur Arch Psychiatry Clin Neurosci. 2018 May. https://doi.org/10.1007/s00406018-0897-z.

29 Upthegrove R, Manzanares-Teson N, Barnes NM. Cytokine function in medication-naive first episode psychosis: a systematic review and meta-analysis. Schizophr Res. 2014 May; 155(1-3):101-8.

30 Gohar SM, Dieset I, Steen NE, Mørch RH, Iversen TS, Steen VM, et al. Association between serum lipid levels, osteoprotegerin and depressive symptomatology in psychotic disorders. Eur Arch Psychiatry Clin Neurosci. 2018. [Epub ahead of print]

31 Köhler CA, Freitas TH, Maes M, de Andrade NQ, Liu CS, Fernandes BS, et al. Peripheral cytokine and chemokine alterations in depression: a meta-analysis of 82 studies. Acta Psychiatr Scand. 2017 May;135(5):373-387.
32 Shah BM, Mezzio DJ, Ho J, Ip EJ; Association of $\mathrm{ABC}$. Association of ABC (HbA1c, blood pressure, LDL-cholesterol) goal attainment with depression and health-related quality of life among adults with type 2 diabetes. J Diabetes Complications. 2015 Aug;29(6):794800 .

33 Nanri A, Eguchi M, Kuwahara K, Kochi T, Kurotani K, Ito R, et al. Macronutrient intake and depressive symptoms among Japanese male workers: the Furukawa Nutrition and Health Study. Psychiatry Res. 2014 Dec; 220(1-2):263-8.

34 Aparicio A, Robles F, López-Sobaler AM, Ortega RM. Dietary glycaemic load and odds of depression in a group of institutionalized elderly people without antidepressant treatment. Eur J Nutr. 2013 Apr;52(3):1059-66.

35 Oishi J, Doi H, Kawakami N. Nutrition and depressive symptoms in community-dwelling elderly persons in Japan. Acta Med Okayama. 2009 Feb;63(1):9-17.

36 Wong PT, Ong YP. Acute antidepressant-like and antianxiety-like effects of tryptophan in mice. Pharmacology. 2001;62(3):151-6.

37 Daffara V, Verdoia M, Rolla R, Nardin M, Marino P, Bellomo G, et al.; Novara Atherosclerosis Study Group (NAS). Impact of polymorphism rs7041 and rs4588 of Vitamin D Binding Protein on the extent of coronary artery disease. Nutr Metab Cardiovasc Dis. 2017 Sep;27(9):775-83.

38 Grave N, Tovo-Rodrigues L, da Silveira J, Rovaris DL, Dal Bosco SM, Contini V, et al. A vitamin $\mathrm{D}$ pathway gene-gene interaction affects low-density lipoprotein cholesterol levels. J Nutr Biochem. 2016 Dec;38:12-7.

39 Stumpf WE. Vitamin D sites and mechanisms of action: a histochemical perspective. Reflections on the utility of autoradiography and cytopharmacology for drug targeting. Histochem Cell Biol. 1995 Dec;104(6):417-27.

40 Stumpf WE, O’Brien LP. 1,25 (OH)2 vitamin D3 sites of action in the brain. An autoradiographic study. Histochemistry. 1987;87(5): 393-406.

41 Pekkinen M, Saarnio E, Viljakainen HT, Kokkonen E, Jakobsen J, Cashman K, et al. Vitamin $\mathrm{D}$ binding protein genotype is associated with serum 25-hydroxyvitamin D and PTH concentrations, as well as bone health in children and adolescents in Finland. PLoS One. 2014 Jan;9(1):e87292. 